\title{
PENGEMBANGAN MANAJEMEN FUNGSIONAL MELALUI PROGRAM DIGITAL PADA USAHA MIKRO DAN KECIL DI MAJALENGKA
}

\author{
Ellen Rusliati ${ }^{1)}$ dan Mulyaningrum ${ }^{2)}$
${ }^{1)}$ Fakultas Ekonomi dan Bisnis, Universitas Pasundan, Bandung ellenrusliati@yahoo.co.id
2)Fakultas Ekonomi dan Bisnis, Universitas Pasundan, Bandung mulyaningrum@unpas.ac.id

\begin{abstract}
Abstrak
Penelitian ini dimaksudkan untuk mengembangkan manajemen fungsional berbasis digital pada Usaha Kecil dan Mikro (UKM) di Kabupaten Majalengka dalam upaya peningkatan kinerja dan daya saing usaha. Metode penelitian yang digunakan adalah deskriptif dan kualitatif, dengan jumlah responden sebanyak 111 pengusaha yang ditentukan berdasarkan accidental sampling dari berbagai bidang usaha. Hasilnya menunjukkan bahwa UKM di Majalengka termasuk kelompok pengusaha off line, namun demikian untuk generasi millenial termasuk potensial untuk dikembangkan menjadi bisnis online dasar bahkan menengah. Bergabungnya pengusaha milenial pada kelompok usaha tertentu menungkinkannya untuk menjalani program digital, berupa peer-to- peer contact, transfer pengetahuan, pelatihan, dan intervensi. Program digital untuk manajemen fungsional, diantaranya pemanfaatan e-commerce, supply chain management, fintech, peer-to-peer lending, pelatihan online, dan kerangka pengetahuan on-line.
\end{abstract}

Kata Kunci: manajemen fungsional; program digital; Usaha Mikro dan Kecil

\begin{abstract}
This research was intended to develop digital-based functional management of Small and Micro Enterprises (SMEs) in Majalengka Regency in an effort to improve business performance and competitiveness. The research method used was descriptive and qualitative, with 111 respondents based on accidental sampling from various business sectors. The results show that SMEs in Majalengka belong to the off line business group, however, for millennials can be categorized potential to be developed into a basic and even intermediate online business. The joining of millennial entrepreneurs in certain business groups allows them to undergo a digital program, in the form of peer-to-peer contact, knowledge transfer, training, and intervention. Digital programs for functional management, including e-commerce, supply chain management, fintech, peer-to-peer lending, online training, and on-line knowledge frameworks.
\end{abstract}

Keywords: functional management; digital program; SMEs

\section{PENDAHULUAN}

Indonesia berkomitmen untuk membangun industri manufaktur yang berdaya saing global melalui percepatan implementasi Industri 4.0. hal ini ditandai dengan peluncuran Making Indonesia 4.0 sebagai sebuah roadmap dan strategi Indonesia memasuki era digital. Dalam roadmap tersebut, Indonesia akan berfokus pada lima sektor manufaktur, yaitu (i) makanan dan minuman, (ii) tekstil dan pakaian, (iii) otomotif, (iv) kimia, serta (v) elektornika (www.kemenperin.go.id). Sektor ini dipilih berdasarkan dampak ekonomi dan kriteria kelayakan investasi yang mencakup ukuran PDB, perdagangan, potensi dampak terhadap industri lain, besaran investasi, dan kecepatan penetrasi pasar.

Digitalisasi menjadi kunci utama Usaha Menengah Kecil dan Mikro (UMKM) di era Revolusi Industri 4.0, demikian diungkapkan Menteri Perhubungan RI, pada hari Selasa 12 Maret 2019 (www.rmoljateng.com). Hingga akhir tahun 2018, baru 5\% UMKM yang telah go digital. Jumlah pelaku UMKM di Korea Selatan mencapai $99,8 \%$ dari unit usaha namun hampir seluruhnya sudah go digital. Target pemerintah adalah 50 juta UMKM go digital, dengan 1.000 techstart-up entrepreneurs pada tahun 2020 (MCIT, 2015). 
Mendorong keterlibatan UMKM dapat meningkatkan pertumbuhan ekonomi tahunan Indonesia sebesar 3\% pertumbuhan tambahan yang dibutuhkan oleh Indonesia untuk menjadi negara berpenghasilan menengah pada tahun 2025. Berdasarkan proyeksi Frost \& Sullivan, pasar e-commerce Indonesia diperkirakan tumbuh pesat $31 \%$ per tahun, $\mathrm{h}$ al ini dikemukakan dengan pertimbangan geliat e-commerce dan ekonomi digital yang potensi pasarnya semakin tak berbatas, watak konsumen Indonesia sudah mendukung berkembangnya pasar digital (www.news.detik.com. 19 April 2018).

Faktor-faktor yang mengindikasikan Revolusi Industri 4.0 ditunjukkan dengan adanya pasar baru, teknologi baru, area produksi baru (pabrik yang terkoneksi), rantai nilai lokal, inti keberlanjutan, model bisnis baru, sumber daya manusia yang fleksibel, dan tenaga ahli sesuai dengan kebutuhan (Propris and Bailey, 2017). Beberapa aspek penting yang menunjukkan ekonomi digital adalah: (a) Transaksi didukung e-commerce, (2) nilai tambah ditunjukkan dari beberapa karaktersitik: enabling industries, platform industries, e-tailers, other digital industries, dan ketergantungan perusahaan pada $e$ commerce, (c) total konsumsi barang ICT yang digunakan dalam produksi, (d) total konsumsi jasa digital, (e) perkiraan nilai atas jasa dan data (Ahmad and Ribarsky, 2018).

Tingkat penggunaan teknologi digital bagi UKM dapat dikelompokkan sebagai berikut (Deloitte, 2015) (1) Bisnis luar jejaring (offline): tanpa akses broadband, tanpa komputer atau smartphone dan tidak memiliki situs jejaring, (2) bisnis online dasar (basic): Ada akses broadband memiliki perangkat digital seperti komputer dan smartphone dan keberadaan online statis, (3) Bisnis online menengah (intermediate): terlibat langsung dalam jejaring sosial, melalui kombinasi situs jejaring yang terintegrasi dengan media sosial, interchat atau utas (thread) pelanggan dalam situs jejaring, (4) Bisnis online lanjutan (advanced): memiliki konektivitas canggih, jejaring sosial terintegrasi, dan kemampuan bisnis e-commerce. Tiwari (2015) mengelompokkan UMKM menjadi 4 kelompok yaitu: technology developers, (2) leading technology users, (3) potential innovators, dan (4) non-innovative SMEs.
Manfaat teknologi digital yang dirasakan oleh UKM dapat diidentifikasi sebagai berikut (Stancombe Research \& Planning. Deloitte Access Economics, 2015): (1) Akses ke pelanggan baru di Indonesia (50,2\%), (2) Peningkatan dalam penjualan dan pendapatn $(35,5 \%)$, (3) Akses ke market baru di luar negri $(33,7 \%)$, (4) Memungkinkan untuk melakukan transaksi yang lebih mudah dengan pelanggan dan pemasok (27,7\%), dan (5) Periklanan yang lebih murah/biaya pemasaran per penjualan $(11,2 \%)$. Pengembangan program digital menurut Jensen, et. al. (2018) meliputi: (1) peer-to-peer contact, yang menginspirasi pengusaha muda untuk menerapkan digitalisasi pada bisnisnya, (2) knowledge transfer, harus dilakukan secara nyata dan dipicu oleh kebutuhan bisnis masing-masing, (3) training, agar dapat menerapkan teknologi untuk tujuan praktis (4) intervention, harus dirancang sebagai tahapan proses bisnis sesuai dengan kebutuhan.

Berdirinya Bandara Internasional Jawa Barat (BIJB) di Kabupaten Majalengka akan mejadi kawasan yang sangat strategis bagi pertumbuhan ekonomi baru untuk wilayah timur Provinsi Jawa Barat yang pada saat ini memiliki mata pencaharian sebagai petani, oleh karena itu, masyarakat perlu dipersiapkan untuk menghadapi peluang dan ancaman perkembangan pasar yang baru. Para pelaku usaha mikro dan kecil perlu diajak untuk berinovasi dan memperhatikan tuntutan pasar, sehingga produk-produk pertanian unggulan dapat diserap pasar dan mempunyai daya saing.

Kondisi pelaku usaha mikro dan kecil di Kabupaten Majalengka pada umumnya memiliki karakteristik: (1) Belum banyak melakukan diversifikasi dan diferensiasi produk yang sesuai dengan tuntutan pasar, (2) Belum memiliki konsep strategi dan taktik produksi dan pemasaran yang terintegrasi agar memiliki keunggulan untuk bersaing, (3) Memiliki jiwa wirausaha yang kuat, namun belum dikembangkan secara optimal.

Perkembangan teknologi informasi yang begitu cepat mendorong pengusaha mikro dan kecil untuk memiliki pola pikir inovasi dan memanfaatkan transformasi digital untuk melakukan bisnis dengan cara yang berbeda. Pengusaha dapat mengakses teknologi untuk meningkatkan produktivitas, 
mengelola biaya, meningkatakan operasi dan mencari peluang untuk meningkatkan pendapatan. Digitalisasi UKM memungkinkannya untuk meningkatkan kepuasan dan loyalitas pelanggan dalam jangka panjang.

Kebutuhan untuk melakukan inovasi dalam bisnis memungkinkan UKM untuk tumbuh dan memperbesar peluang bisnis. UKM dapat memprioritaskan pengeluaran ICT pada 6 area berikut untuk meningkatkan bisnis melalui penghematan waktu dan efisiensi operasi, yaitu: (1) Mengelola bisnis, (2) Meningkatkan Penjualan,

Meningkatkan Pasar, (3) Mengelola Keuangan, (4) Menyederhanakan perbankan, (5) Mengelola Tenaga Kerja (UOB, 2018).

Perubahan sangat penting, agar perusahaan dapat bersaing, elastis, fleksibel, dan berkembang dalam jangka panjang. Menjadi tantangan bagi UMKM untuk mulai melakukan inovasi dan transformasi, meningkatkan efisiensi dengan memanfaatkan potensi yang dimiliki dan memperkuat bisnisnya dengan menggunakan ekonomi digital. Data yang terintegrasi memerlukan jaringan dari berbagai sistem teknologi informasi daik di dalam maupun antar perusahaan, Dengan cara ini, area fungsional, seperti pembelian, produksi, dan penjualan akan mengubah data secara real time. Hal ini tidak mudah bagi usaha mikro dan kecil, yang memiliki keterbatasan sumber, untuk memanfaatkan kemajuan teknologi sebagai solusi dan pemnfaatan dalam bisnis (Schroder, 2016).

Perkembangan media digital bagi kesiapan sumber daya manusia untuk mengiringi laju perkembangannya dan dibutuhkan upaya untuk mengantisipasi dampak yang bersifat negatif. Literasi digital dilakukan sebagai upaya membangun pemahaman akan keberadaan media digital (Widyastuty, 2016). Tingkat partisipasi digital dapat meliputi sumber daya manusia, produksi, pemasaran, keuangan, manajemen umum, kontrol kualitas, teknologi, gugus industri, dan pusat inovasi UMKM.

\section{METODE}

Metode penelitian yang dilakukan pada penelitian ini adalah deskriptif kualitatif. Unit analisis adalah 111 pengusaha mikro dan kecil di Majalengka yang bergerak di berbagai bidang, dengan accidental sampling, karena tidak ada data yang tersedia untuk kelompok usaha mikro. Pengumpulan data dilakukan melalui observasi, kuesioner, dan wawancara yang dilakukan pada tahun 2017 dan 2018, meliputi berbagai aspek manajemen fungsional (pemasaran, sumber daya manusia, keuangan, dan operasi).

\section{HASIL}

Berdasarkan jenis kelamin, pengusaha yang berhasil diwawancara laki-laki sebanyak 59 orang (53\%) dan perempuan 52 (47\%). Berdasarkan sisi usia, responden yang menjadi subjek penelitian ini terbagi dalam beberapa kelompok umur paling banyak ditempati kelompok berusia lebih dari 37 tahun mencapai 71 orang (64\%) selanjutnya responden berusia 21-37 tahun mencapai 40 orang (36\%). Berdasarkan latar belakang pendidikan terakhir responden didominasi oleh yang berpendidikan SMA ke bawah mencapai 95 orang (86\%), sisanya sebanyak 16 orang (14\%) berpendidikan atau kuliah di perguruan tinggi. Berdasarkan bidang usaha didominasi manufaktur makanan mencapai 86 orang $(77 \%)$, bidang usaha manufaktur bukan makanan berjumlah 20 orang (18\%), dan sebanyak 5 orang (5\%) di bidang usaha Jasa.

Manajemen pemasaran yang sudah diterapkan meliputi: (1) Segmenting, targeting, dan product posisitioning sudah dilakukan oleh beberapa pengusaha namun masih banyak yang belum melakukannya. Pengusaha dengan pendidikan lebih tinggi melakukan segmentasi pelanggan, kemudian menentukan produk, harga, cara distribusi yang dihasilkan untuk masing-masing segmen, (2) Penjualan produk dapat dilakukan secara mandiri, bergabung dengan pengusaha lain di BUM Desa, atau konsinyasi dengan pengusaha yang lebih besar atau toko serba ada. Pengusaha yang lebih maju dapat menampung produksi pengusaha lain sebagai tempat pemasaran dengan merk sendiri ataupun berdasarkan kesepakatan. 
Manajemen operasi, meliputi (1) Input: Beberapa pengusaha menggunkan bahan baku lokal, namun untuk keperluan kualitas produk yang baik maka menggunakan bahan baku berasal dari luar Majalengka, misalnya beras ketan untuk bahan dasar raginang didatangkan dari Jawa Tengah, bayam untuk keripik bayam dari Lembang, bawang untuk bawang goreng dari Brebes, kain untuk kerudung dan celana jean dari Bandung, kacang polong dari importir, terigu untuk pangsit goreng dari Bandung, kedelai, minyak goreng untuk tahu dan tempe dari Bandung, (2) Proses : Beberapa pengusaha melakukan proses produksi secara manual dan beberapa diantaranya menggunakan mesin proses produksi sederhana, seperti mesin penggiling tepung ubi, mesin penggoreng bawang, mesin oven pengering buah, (3) Output: Pengusaha menghasilkan produk umum yang tidak memiliki ciri khas, seperti keripik singkong, pisang, ubi, jamur, opak, tahu, tempe, bawang goreng, pangsit goreng, kacang polong, dodol mangga/pisang/jambu biji celana jean, kerudung, T-shirt yang juga tersedia di daerah lain. Pembeda mulai dimunculkan dengan mencantumkan ciri khas seperti Tshirt dengan design gambar Majalengka, dodol mangga/pisang/jambu biji khas Majalengka. Penonjolan ciri khas daerah masih perlu dipupuk dan ditelusuri sehingga membentuk identitas Majalengka.

Manajemen keuangan, meliputi Sumber Dana: Pengusaha lebih banyak menggunakan modal sendiri dalam menjalankan usahanya, dengan alasan aman dan terbebas dari kewajiban membayar bunga dan mencicil hutang, (2) Penggunaan Dana: Dana lebih banyak digunakan untuk kepentingan modal kerja, keperluan modal sehari-hari. Pengadaan aktiva tetap dilakukan secara bertahap, jika memiliki kelebihan dana dan kepastian pemasaran, (3) Pengelolaan Assets: Pengusaha mikro dan kecil lebih berkepentingan dengan pengelolaan modal kerja. Kelemahannya adalah pencatatan keuangan yang belum dilakukan sesuai dengan ketentuan, sehingga belum mampu menyediakan laporan keuangan untuk dapat digunakan sebagai alat pengukur kinerja dan perencanaan.

Manajemen sumber daya nanusia: (1) Jiwa kewirausahaan pengusaha Majalengka sudah memadai, namun dukungan dan keberpihakan pemerintah untuk melindungi dan membantunya senantiasa diperlukan untuk memperkuat daya saing. Budaya lebih terhormat menjadi pegawai negri sipil atau karyawan perusahaan masih lebih terhormat dan memiliki kepastian dibandingkan dengan pengusaha yang merintis usaha dari kecil, serta risiko merugi bahkan kebangkrutan menjadi tantangan bagi pengusaha mikro dan kecil Majalengka.

\section{PEMBAHASAN}

Berdasarkan hasil penelitian, maka pengusaha mikro dan kecil Majalengka belum menerapkan digital dalam usahanya. Jika dihubungkan dengan pengelompokkan pengusaha menurut Deloitte (2015), maka termasuk kelompok 1, yaitu pengusaha yang bekerja secara offline, memiliki smartphone, namun belum dimanfaatkan untuk keperluan bisnis secara maksimal. Jika menggunakan Tiwari (2015) yang mengelompokkan UMKM berdaarkan pemanfaatan teknologi, maka pengusaha generasi milenial dapat dikelompokkan sebagai potential innovators. Mereka dapat menggunakan teknologi sebagai sumber inovasi bisnis, karena tingkat penyesuaian terhadap teknologi lebih cepat.

Peer to peer contact dapat dilakukan dengan membuat jejaring diantara para pengusaha, beberapa yang sudah berdiri diantaranya adalah (1) Forum Pengusaha Muda Majalengka (FPMM), (2) Komunitas Pengusaha Cirebon, Majalengka. Kuningan, Sumedang Indramayu, (3) Saung Suung Yuceu, (4) Generasi Pesona Indonesia (GenPI), (5) Komunitas Saung Eurih. Setiap kelompok dapat membangun jejaring dengan pengusaha lain, walaupun demikian harus dirancang secara hati-hati dan diterapkan untuk memperoleh manfaat dalam peluang pasar global dan minimalisasi ancaman persaingan yang cenderung meningkat (Oclo, et.al., 2014).

Jejaring ini selain digunakan sebagai sarana komunikasi juga digunakan sebagai sarana untuk transfer pengetahuan, pelatihan, dan intervensi. Transfer pengetahuan dapat dilakukan secara nyata dan dipicu oleh kebutuhan bisnis masingmasing. Pelatihan, agar dapat menerapkan teknologi untuk tujuan praktis. Intervensi, 
harus dirancang sebagai tahapan proses bisnis sesuai dengan kebutuhan.

Tabel 1 menunjukkan hambatan dan solusi digital untuk mengatasi masalah manajemen fungsional yang dihadapi UMKM
Majalengka. Tabel ini dapat dikembangkan lebih lanjut sesuaia dengan permasalahan yang dihadapi UMKM.

Tabel 1. Hambatan dan Solusi Digital yang Ditawarkan bagi UMKM Majalengka

\begin{tabular}{|c|c|c|}
\hline No & Hambatan & Solusi \\
\hline 1 & $\begin{array}{l}\text { Akses Pasar dan Rantai } \\
\text { Nilai: } \\
\text { UMKM mengalami kesulitan } \\
\text { memperoleh informasi } \\
\text { tentang pasar dan rantai } \\
\text { nilai, dihubungkan dengan } \\
\text { tenaga kerja, lingkungan, } \\
\text { sosial dan standar kualitas }\end{array}$ & $\begin{array}{l}\text { 1. Ekonomi digital menyediakan biaya yang rendah untuk } \\
\text { mengatasi hambatan mengakses pasar dan jumlah } \\
\text { pelanggan yang tidak diperkirakan akan meningkatkan } \\
\text { penjualan. } \\
\text { 2. Jangkauan pasar dapat diperluas dengan mendorong } \\
\text { UMKM untuk mengadopsi teknologi digital melalui } \\
\text { penyediaan solusi managed service operational layanan } \\
\text { e-commerce dan mempercepat pengembangan } \\
\text { advertising agar memperoleh sarana promosi melalui } \\
\text { sosial media marketing yang efektif dan efisien. } \\
\text { 3. Aplikasi Teknologi Tepat Guna digitalisasi UMKM dalam } \\
\text { proses produksi dan pemasaran akan meningkatkan } \\
\text { kapasitas produksi dan efisien dari waktu sehingga akan } \\
\text { meningkatkan daya saing bagi UMKM dan masyarakat } \\
\text { lain akan menjadi peluang usaha untuk mengembangkan } \\
\text { wirausaha bersama-sama. } \\
\text { 4. Penetrasi Pasar: mengakses pasar yang ada dengan } \\
\text { teknik pemasaran yang baru, promosi melalui media } \\
\text { sosial dan layanan e-commerce. } \\
\text { 5. Pengembangan Produk: penelusuran ide kreatif } \\
\text { mengenai produk yang diinginkan pelanggan juga } \\
\text { menganalisis produk yang dihasilkan pesaing, melalui } \\
\text { media sosial. }\end{array}$ \\
\hline
\end{tabular}

2 Akses Keuangan:

Pendanaan menggunakan hutang bagi UMKM dan pengusaha menjadi hambatan; alternatif modal sendiri yang terbatas dan berfluktuasi

3 Akses Keahlian:

Pertumbuhan

UMKM terkendala pada terbatasnya keahlian managerial dan keahlian khusus, seperti teknologi produksi dan informasi.

4 Aspek Operasi:

Proses operasi dijalankan secara manual.
Ekonomi digital menawarkan model pendanaan baru seperti fintech, dan peer-to-peer lending. Data mengenai kinerja UMKM akan menjadi alat dan proses yang baru.

Ekonomi digital memberikan solusi untuk mengatasi keterbatasan dalam mengakses keahlian melalui pelatihan online dan kerangka kerja pengetahuan online.

1. Implementasi supply chain management yang dapat memberikan kemudahan bagi UKM dalam mendapatkan bahan baku, mendorong UKM untuk menggunakan aplikasi online rekruitmen tenaga kerja, dan menyediakan management inventory system untuk mempermudah pengelolaan barang.

2. Aplikasi Teknologi Tepat Guna digitalisasi UMKM dalam proses produksi dan pemasaran akan meningkatkan 
kapasitas produksi dan efisien dari waktu sehingga akan meningkatkan daya saing bagi UMKM dan masyarakat lain akan menjadi peluang usaha untuk mengembangkan wirausaha bersama-sama.

5 Pengusaha start up digital yang berkelanjutan
Pembentukan pola pikir, membangun sebuah tim, pengembangan produk, membangun bisnis model, memetakan target pasar, strategi untuk meluncurkan produk di pasar.

Sumber: Kasap (2016); Slamet, et. al. (2016); Diningrat, et. al. (2017); Komunikasi dan Informatika Indonesia (2016); Rusliati, et. al. (2018) diolah

Perkembangan teknologi informasi membantu dalam rangka modernisasi sistem usaha dasar seperti akuntansi, pembayaran gaji, dan manajemen rantai supply dapat meningkatkan secara pesat kinerja usaha dan produktivitas tenaga kerja. Fintech (Financial Technology) memberi manfaat bagi UMKM berupa (www.bi.go.id.) : (1) memberikan pilihan produk, (2) kualitas layanan lebih baik, (3) harga lebih murah. UMKM harus dapat terlacak secara digital karena untuk membangun kredibilitas karakter. Fintech akan menganalisis lewat digital, sehingga UMKM harus rajin update, demikian dikemukakan Deputi Akses Permodalan Badan Ekonomi Kreatif/BEKraf $\begin{array}{llll}\text { pada } & 19 & \text { April } & 2016\end{array}$ (www.cnn.indonesia.com.).

Faktor-faktor yang mendukung pelaku UKM untuk menggunakan fintech adalah berupa kenyamanan, kemanan, keseuaian transaksi, kemudahan, serta bisnis. Hal-hal yang berkaitan dengan faktor pendukung ini adalaj berupa kemudahan pencatatan, proses transaksi, serta peningkatan penjualan. Faktor penghambat pada penggunaan layanan ini adalah implementasi teknologi, biaya, serta kesiapan infrastruktur berupa kebutuhan pada beberapa titik saat mengimplementasikan teknologi ini (Luckandi, 2018).

Pemanfaatan jasa keuangan fintech memang menawarkan banyak manfaat, namun harus dilakukan secara hati-hati, karena dapat meningkatkan risiko. Pemahaman manajemen keuangan sangat diperlukan, untuk pengambilan keputusan keuangan penggunaan dana, sumber dana, dan manajemen assets. Kesalahan dalam pengambilan keputusan dapat mengakibatkan perusahaan masuk dalam kesulitan keuangan, lebih dianjurkan untuk mengakses fintech berbasis syariah, karena mayoritas pengusaha beragama Islam secara taat.

\section{KESIMPULAN}

Berdasarkan hasil penelitian dan pembahasan, dapat ditarik kesimpulan bahwa mayoritas UKM di Kabupaten Majalengka termasuk kelompok pengusaha off line, karena belum memanfaatkan smartphone yang dimiliki untuk keperluan bisnis. Pengusaha yang termasuk generasi millenial memiliki potensi untuk dikembangkan menjadi bisnis online dasar bahkan menengah, karena tingkat penyesuaiannya yang lebih cepat terhadap teknologi informasi sehingga dapat terlibat langsung dalam jejaring sosial dan interchat dengan pelanggan dan pemasok. Bergabungnya pengusaha milenial pada kelompok usaha tertentu menungkinkannya untuk menjalani program digital, berupa peer-to-peer contact, transfer pengetahuan, pelatihan, dan intervensi. Program digital untuk manajemen fungsional, diantaranya pemanfaatan e-commerce, supply chain management, fintech, peer-to-peer lending, pelatihan online, dan kerangka pengetahuan on-line.

\section{DAFTAR PUSTAKA}

Ahmad, N. \& Ribarsky, J. (2018). Towards a framework for measuring the digital economy. Paper prepared for the 16th Conference of IAOS, OECD Headquarters, Paris, France, 19-21 September.

Deloitte Access Economics. (2015). UKM Pemicu Kemajuan Indonesia. Instrumen Pertumbuhan Nusantara.

Diningrat, D. S., Maulana, B., Gultom, E. S. (2017). Digitalisasi UMKM makanan sehat Desa Sahkhuda Bayu Kabupaten Simalungun Sumatera Utara. Prosiding 
Seminar Nasional Pengabdian Mayarakat. LPM UNIMED.

Jensen, H. V., Tofalleti, S., Thornley, C., \& Murnane, S. Grand Coalition for Digital Jobs. Digital Skills for SMEs.

Kasap, E. I. (2016). Digital economy: Opportunities and challenges for SME development. 30th $\mathrm{CACCl}$ Conference, November 24.

Komunikasi dan Informatika Indonesia. (2016). Buku putih. http://eppid.kominfo. go.id.

Luckandi, D. (2018). Analisis transaksi pembayaran menggunakan fintech pada UMKM di Indonesia: Pendekatan adaptive structuration theory. https://dspace.uii. ac.id

Oclo, C. E., Akaba, S., Worwui-Brown, D. K. (2014). Globalization and competitiveness: Challenges of small and medium entrprises (SMEs) in Accra, Ghana. International Journal of Business and Social Science, 5(4), 287-296.

Propris, L. de, \& Bailey, B. (2017). Disruptive industry 4.0. Globalisation human capital regional growth and the $4^{\text {th }}$ industrial revolution, Bologna $20^{\text {th }}$ October.

Rusliati, E., Mulyaningrum, Sufyani, M. A. (2018). Development strategies of micro business in Majalengka Regency. Trikonomika, 17(2), 101-108.

Schroder, C. (2016). The Challenge of Industry 4.0 Small and Medium-sized Enterprises. July. A good society - social democracy.

Slamet, R., Nainggolan, B., Roessobiyatno, Ramdani, H., Hendriyanto, A., \& IIma, L. L. (2016) Strategi pengembangan UKM digital dalam menghadapi era pasar bebas. Jurnal Manajemen Indonesia, 16(2), 136-147.

Tiwari, M. K. (2014). Competitiveness of SMEs through different strategies. IOSR Journal of Business and Management (IOSR-JBM), 16(3), 66-68.

UOB. 2018. Investasi Teknologi Merupakan Salah Satu Prioritas Utama UKM Indonesia Dalam Meningkatkan Daya Saing.

Widyastuti, D. A. R., Nuswantoro, R., \& Sidhi, T. A. P. (2016). Literasi digital pada perempuan pelaku usaha produktif di Daerah Istimewa Yogyakarta. Jurnal ASPIKOM, 3(1), 1-15.

www.bi.go.id. www.cnn.indonesia.com www.kemenperin.go.id www.news.detik.com www.rmoljateng.com 
Rusliati \& Mulyaningrum / Pengembangan Manajemen Fungsional melalui Program Digital ... 